\title{
A prospective study of outcome in infertility patients diagnosed with genital tuberculosis
}

\author{
Sumitra Yadav*, Neha Kumar
}

Department of Obstetrics and Gynecology, MY Hospital and MGM Medical College, Indore, Madhya Pradesh, India

Received: 03 August 2019

Revised: 21 December 2019

Accepted: 27 December 2019

\author{
*Correspondence: \\ Dr. Sumitra Yadav, \\ E-mail: drsumitrayadav@yahoo.co.in
}

Copyright: ( ) the author(s), publisher and licensee Medip Academy. This is an open-access article distributed under the terms of the Creative Commons Attribution Non-Commercial License, which permits unrestricted non-commercial use, distribution, and reproduction in any medium, provided the original work is properly cited.

\begin{abstract}
Background: Tuberculosis is an increasing health problem worldwide with around 9.6 billion new cases reported every year. Female genital tuberculosis (FGTB) has a varying incidence ranging from a very low of $0.69 \%$ in developed nations to as high as $19 \%$ in developing nations like India. The average incidence of infertility due to tuberculosis is $5-10 \%$ worldwide.

Methods: The study was a hospital based prospective clinical study, from September 2014-2017 with sample size of 355 infertility cases. Endometrial sampling and diagnostic hystero-laparoscopy were used for diagnosis. Endometrial sample subjected for both the test CBNAAT and HPR was used for confirmation of positive patients. Inclusion criteria were, infertile patients diagnosed with genital tuberculosis who were then given treatment. Patients diagnosed to have infertility due to causes other than TB were excluded from the study. Highly suspected cases and those who were willing underwent diagnostic laparoscopy.

Results: Out of 355 cases of infertility, 83 were because of genital TB, received treatment out of which 32 conceived. CBNAAT was very sensitive than histopathology or laparoscopy. The live birth rate and conception rate were $20.24 \%$ and $38.09 \%$ respectively.

Conclusions: CBNAAT is OPD based economical test (free by GOI), very sensitive and picked up more cases than histopathology or laparoscopy. The live birth rate and conception rate were found to be higher than other studies possible due to intervention at an earlier stage of the disease process. This test should be widely used by gynecologist for early detection of genital tuberculosis.
\end{abstract}

Keywords: Anti tubercular treatment, Cartridge based nucleic acid amplification test, Conception rate, Female genital tuberculosis, Infertility, Live birth rate

\section{INTRODUCTION}

Tuberculosis is an increasing public health problem worldwide, as 10.0 million people reportedly contracted the infection, and 1.6 million died from the disease (including 0.3 million people with HIV) (WHO, 2018). ${ }^{1}$ Over $95 \%$ of TB deaths occur in low- and middle-income countries. It has a wide range of infection and morbidity with the incidence as low as 0.69 in developed nations and as high as $19 \%$ in India (3102-12136-1-PB). ${ }^{2}$ India and China alone account for $40 \%$ of the burden. In developing countries like India genital tract tuberculosis is identified as an important cause of infertility (FertilSciRes316-378688_103108). ${ }^{3}$ The reported figures show that in India, around $0.75 \%$ to $1 \%$ of total gynaecological complaints are associated with genital tuberculosis, although this number varies from place to place (Arora and Arora). ${ }^{4}$ Female genital tuberculosis 
(FGTB) is still a major cause of infertility in India in spite of the availability of specific therapy (Nadgouda et al). ${ }^{5}$ Genital tuberculosis also accounts for $9 \%$ of all cases of extrapulmonary tuberculosis. Around $5 \%$ of all pelvic infections are cases of genital tuberculosis and further it accounts for $10 \%$ of all cases of pulmonary tuberculosis (Arora and Arora; Dawn). ${ }^{6}$ Genital tuberculosis affects all pelvic structures, fallopian tubes $100 \%$, endometrium 50$60 \%$ and ovaries 20-30\% (JCytol2831412319699_062636). ${ }^{7}$ Overall, it leads to infertility irrespective of which structure is infected. Genital tuberculosis not only causes tubal obstruction and dysfunction but also impairs implantation due to endometrial involvement and ovulatory failure from ovarian involvement (Roy and Roy). ${ }^{8}$ The average worldwide incidence due to genital tuberculosis is $5-10 \%$. The fallopian tubes get blocked while in the endometrium there is non-reception and finally Asherman's syndrome. This study aimed to evaluate the incidence of genital tuberculosis among infertile women and provide ATT (anti tubercular treatment) in genital TB patients. Furthermore, authors determined the incidence of pregnancy and its outcome among those treated for TB.

\section{METHODS}

The study was hospital based prospective clinical study. The duration was from September 2014-2017 (4 years) with a sample size of 355 . The study was undertaken from the year 20014 to 2017 at MY Hospital and MGMMC, a teaching institute in Madhya Pradesh. Women from all couples seeking treatment for infertility between 20014 and 2017 were screened for inclusion in the study. All couples were investigated and managed according to the standard protocol followed at the centre. Endometrial samples were obtained by endometrial aspiration or curettage, done as a stand-alone test, while highly suspected cases and those willing underwent diagnostic laparoscopy. One part of the biopsy of endometrial tissue was subjected to histopathologic examination and the second part was sent to the laboratory for CBNAAT testing. Endometrial samples were obtained by gentle curettage of the endometrium and kept in sterile containers with normal saline to avoid contamination. Histopathologic examination of endometrial biopsies did not reveal any presence of acidfast bacilli, granuloma formation or other findings suggestive of TB. The cartridge based nucleic acid amplification test (CBNAAT) (gene expert) was used for sampling/confirmation of positive patients.

Laparoscopy and histopathological reporting were used for evaluation and diagnosis. The inclusion criteria for the samples were; infertile patients diagnosed with genital tuberculosis and if any causes other than TB were found, those patients excluded from the study. All patients enrolled in the study underwent endometrial sampling for CBNAAT and histopathological reporting. Highly suspected cases and those who were willing underwent diagnostic laparoscopy.

\section{CBNAAT}

Nucleic acid amplification (NAA) tests represent a major advance in the diagnosis of TB. ${ }^{9}$ With the use of amplification systems, nucleic acid sequences unique to MTB can be detected directly in clinical specimens, offering better accuracy than microscopy and greater speed than culture. Advanced molecular methods such as polymerase chain reaction (PCR), a type of NAA system, have shown very promising results for early and rapid diagnosis of the disease due to its detection limit of one to ten bacilli in various clinical samples. ${ }^{10}$

\section{Histopathology}

Laparoscopic and hysteroscopic examination are part of the standardized protocol for evaluation of infertile women. Several reports have described findings suggestive of GTB. Endometrial sampling (EB) with or without laparoscopy is a simple out-patient procedure that can be used to obtain tissue samples in a nondestructive manner, including a repeat biopsy in subsequent cycles. The clinical yield of EB is fairly good, which makes it a highly cost-effective test. Demonstration of mycobacteria on smear and culture, used as a gold standard, is the most specific test for diagnosis of TB. Although mycobacterial demonstration in examination of sputum is the mainstay of the diagnosis of pulmonary TB where there is a high bacterial burden, the very low sensitivity for diagnosis of paucibacillary disease limits its practical utility in extra-pulmonary TB. ${ }^{11}$

\section{Laparoscopy}

Diagnostic laparoscopy was performed and a careful evaluation of the fallopian tubes, ovaries, pelvic peritoneum, pouch of Douglas and peritoneal cavity was done. Features suggestive of genital tuberculosis were looked for by noting the presence of: suprahepatic adhesions, pelvic adhesions, pelvic congestion, bowel/omental adhesions, peritubal adhesions, cornual block, delayed spillage, fimbrial phimosis, hydrosalphynx, granulomas, short tubes, sacculations/beaded tubes, rigid tubes, TO mass, other incidental findings: fibroids, endometriosis, PCOS. ${ }^{12}$

\section{RESULTS}

Total 355 patients with female factor of infertility were enrolled in study. Some (315 cases of infertility) were subjected to endometrial sampling, which was sent for cartridge based nucleic acid amplification test (CBNAAT) and for histopathological examination for confirmation and few (45 cases of infertility) were taken for diagnostic hystero- laparoscopy. The duration of infertility varied from 1-5 years. Out of 315 cases which was subjected for endometrial biopsy only 61 cases were positive for genital tuberculosis. Out of 61 cases, 60 cases were confirmed by CBNATT and Only one case showed 
suspected TB on histopathological diagnosis but without tuberculoma. Out of 45 patients underwent diagnostic hystero-laparoscopy, of which 22 were suspected to be positive for tuberculosis. A total of 83 patients were identified as candidates for ATT and treatment was started for all.

As shown in Table 1, the Incidence of genital tuberculosis in the study was $23.38 \%$.

Table 1: Incidence of genital tuberculosis.

Incidence of genital tuberculosis among infertile women

\begin{tabular}{|lll|}
\hline Genital TB & No. of cases & $\%$ of cases \\
\hline Genital TB positive cases & 83 & 23.38 \\
\hline Genital TB negative cases & 272 & 76.62 \\
\hline Total cases of infertility & 355 & 100 \\
\hline
\end{tabular}

As shown in Table 2, Out of 355 cases of infertility, 45 cases were subjected for IPD DHL and 315 cases for Endometrial sampling on OPD basis. Only 83 cases of infertility were due to genital tuberculosis. Out of 83 case of genital tuberculosis, 22 cases (48.88\%) were diagnosed on DHL and 61 case (19.37) were diagnosed on endometrial sampling.

As shown in Table 3, total 315 case of infertility were subjected for endometrial sampling send for both tests, CBNAAT test and histopathology examination, only 61 cases were positive for tuberculosis, out of which 60 cases $(19.05 \%)$ diagnosed on CBNATT test and only 1 case $(0.32 \%)$ on histopathological examination but without tuberculoma.

As shown in Table 4, of the 83 patients who underwent treatment with ATT, only 32 cases conceived (38.55\%).

Table 2: Procedure used for diagnosis and confirmation of genital tuberculosis.

\begin{tabular}{|llll|}
\hline Procedure done & Total no. of cases & No. of case positive for genital TB & \% of genital tb positive case \\
\hline DHL & 45 & 22 & 48.88 \\
\hline Endometrial sampling & 315 & 61 & 19.37 \\
\hline Total no. of infertility case: & 355 & 83 & 23.38 \\
\hline
\end{tabular}

Table 3: Methods used for confirmation on endomaterial sampling.

Diagnostic methods used on endometrial sampling on 315 cases of infertility for confirmation of genital TB

\begin{tabular}{|lll|} 
Method & $\begin{array}{l}\text { No. of } \\
\text { confirmed cases }\end{array}$ & $\begin{array}{l}\text { \% of confirmed } \\
\text { cases }\end{array}$ \\
\hline CBNAAT & 60 & 19.05 \\
\hline Histopathology & 1 & 0.32 \\
\hline Total & $\mathbf{6 1}$ & $\mathbf{1 9 . 3 7}$ \\
\hline
\end{tabular}

Table 4: Effect of ATT treatment on conception rate.

\begin{tabular}{|c|c|c|}
\hline \multicolumn{3}{|c|}{$\begin{array}{l}\text { Effect Of ATT on genital TB In terms of } \\
\text { conception }\end{array}$} \\
\hline Effect of ATT on conceptio & No. of case & $\%$ of cases \\
\hline No. of women conceived & 32 & 38.55 \\
\hline No. of women not conceived & 51 & 61.45 \\
\hline $\begin{array}{l}\text { Total no. of women started } \\
\text { on ATT }\end{array}$ & 83 & 100 \\
\hline
\end{tabular}

Table 5, shows effect duration of ATT treatment on conception rate, of which $13(40.63 \%)$ conceived while treatment was ongoing whereas 19 patients $(59.37 \%)$ conceived after completion of treatment.

Thus, the conception rate among those treated was 38.09 $\%$.
Table 6 shows pregnancy outcome after conception, out of 32 cases who got conceived after ATT, there were 14 csaes $(43.75 \%)$ of blighted ovums, 1 case $(3.12 \%)$ tubal ectopic pregnancy and 17 progressed beyond the age of viability.

Table 5: Effect of duration of ATT on conception rate.

Effect of duration Of ATT for treatment of genital TB on conception rate

\begin{tabular}{|lll|}
\hline $\begin{array}{l}\text { Duration of } \\
\text { treatment }\end{array}$ & $\begin{array}{l}\text { No. of cases } \\
\text { conceived }\end{array}$ & $\begin{array}{l}\text { \% of cases } \\
\text { conceived }\end{array}$ \\
\hline With ongoing T/T & 13 & 40.63 \\
\hline $\begin{array}{l}\text { After 6 months of } \\
\text { T/T }\end{array}$ & 19 & 59.37 \\
\hline $\begin{array}{l}\text { Total no. of women } \\
\text { conceived }\end{array}$ & 32 & 100 \\
\hline
\end{tabular}

Table 6: Pregnancy outcomes after ATT.

\begin{tabular}{|lll|}
\hline Pregnancy outcome & After & ATT \\
Pregnancy outcome & $\begin{array}{l}\text { No. of } \\
\text { cases }\end{array}$ & $\begin{array}{l}\text { \% of } \\
\text { cases }\end{array}$ \\
\hline Blighted ovum & 14 & 43.75 \\
\hline Ectopic pregnancy & 1 & 3.12 \\
\hline Preterm delivery & 3 & 9.38 \\
\hline Term delivery & 14 & 43.75 \\
\hline Total no. of women conceived & 32 & 100 \\
\hline
\end{tabular}


Of these 17 pregnancies that progressed 3 cases $(9.38 \%)$ delivered preterm, 14 cases $(43.75 \%)$ delivered term. This resulted in a live birth rate of $20.24 \%$. Incidence of primary and secondary infertility was $78 \%$ and $22 \%$ respectively. Among different studies the incidence of genital tuberculosis ranged from $3 \%$ for Tripathy et al, to $48.6 \%$ for Singh et al.

\section{DISCUSSION}

The conception rate $(38.55 \%)$ and live birth rate $(20.24 \%)$ were higher in our study than others such as that of Grace et al, where both the two rates did not go beyond $10 \% .{ }^{13}$ It is important to note that, out of the 83 patients who underwent treatment, 32 conceived, of which 13 (40.6\%) conceived while treatment was ongoing whereas 19 patients $(59.4 \%)$ conceived after treatment. This clearly indicates the positive effect of the treatment on pregnancy, and the percentage of conception is highly significant. Authors speculate this may be because authors did not wait for definite diagnosis to initiate treatment. It is well understood that a definite diagnosis is very difficult to point out and by the time such a conclusion may be reached, complete damage may have been done and it is very likely that the patient becomes completely infertile by then. An index of suspicion and early initiation of treatment would be the only solution to help such patients. However, conception does not always lead to a full-term pregnancy, and may result in adverse outcomes such as blighted ovum or ectopic pregnancies as shown in Table 6. Blighted ovum or missed abortion occurs in the very early weeks of pregnancy and is an ultrasound diagnosis. An ectopic pregnancy occurs when the embryo implants in an extra uterine site. In cases of tuberculosis, this is most commonly due to the irreversible changes in the anatomy of the fallopian tubes. Nonetheless, our study indicates that, despite the possibilities of these outcomes, the probability of positive outcomes of early intervention to prevent these irreversible changes in the reproductive anatomy is higher. This may serve useful in handling future cases and reduce the negative outcomes to a significant level.

Newer technologies allow genital tuberculosis to be identified at an earlier stage and enable us to provide treatment. However, the take-home rate for a healthy baby is much different than the conception rate which reveals that even though patients may conceive, they are to be considered high risk till they deliver.

\section{ACKNOWLEDGMENTS}

Authors would like to thank Mr A.K. Kharate, (JD-TB and State TB Officer) who believed in authors enough to provide all access to data and support from the state TB program. Dr C.V. Kulkarni, Professor and Head Department of Pathology, who gave priority for using gene expert and all the histopathological services of the department.

\section{Funding: No funding sources Conflict of interest: None declared \\ Ethical approval: The study was approved by the Institutional Ethics Committee}

\section{REFERENCES}

1. Global Tuberculosis Report, 2018. Available at: https://apps.who.int/iris/bitstream/handle/10665/.../978924 1565646-eng.pdf. Accessed 14 ${ }^{\text {th }}$ April 2019

2. Shende P, Valecha SM, Gandhewar M, Dhingra D. Genital tuberculosis and infertility. Int J Reprod Contracept Obstet Gynecol. 2017;6:3514-7.

3. Sharma JB, Dharmendra S, Agarwal S, Sharma E. Genital tuberculosis and infertility. Fertil Sci Res. 2016;3:6-18.

4. Arora R, Rajaram P, Oumachigui A, Arora VK. Prospective analysis of short course chemotherapy in female genital tuberculosis. Int $\mathbf{J}$ Gynecol Obstet. 1992;38(4):311-4.

5. Nadgouda SS, Mukhopadhyaya PN, Acharya A, Nagee A, Kunjadia PD. A study on genital tuberculosis and infertility in Indian population. Clin Pract. 2010;2:1.

6. Dawn CS. Pelvic infections; In: Dawn C.S.; ed Textbook of Gynaecology and Contraception: 9th ed.; Calcutta: Arati Dawn; 1998; 321Roy H, Roy S. Use of polymerase chain reaction for diagnosis of endometrial tuberculosis in high risk sub fertile women in an endemic zone. J Obstet Gynecol India. 2003;53:260

7. Seth A, Kudesia M, Gupta K, Pant L, Mathur A. Cytodiagnosis and pitfalls of genital tuberculosis: A report of two cases. J Cytology/Indian Acad Cytol. 2011;28(3):141.

8. Roy H, Roy S. Use of polymerase chain reaction for diagnosis of endometrial tuberculosis in high risk subfertile women in an endemic zone. J Obstet Gynecol India. 2003;53:260.

9. Singh UB, Seth P. PCR diagnosis of tuberculosis Experience in India. Indian J Pediatr. 2002;69 Suppl 1:S20-4.

10. Eisenach KD, Sifford MD, Cave MD, Bates JH, Crawford JT. Detection of Mycobacterium tuberculosis in sputum samples using a polymerase chain reaction. Am Rev Respir Dis. 1991;144:1160-3.

11. Jindal UN, Bala Y, Sodhi S, Verma S, Jindal S. Female genital tuberculosis: early diagnosis by laparoscopy and endometrial polymerase chain reaction. The Int $\mathrm{J}$ Tuberculosis Lung Dis. 2010;14(12):1629-34.

12. Arpitha VJ, Savitha C, Nagarathnamma R. Diagnosis of genital tuberculosis: correlation between polymerase chain reaction positivity and laparoscopic findings. Int J Reprod Contracept Obstet Gynecol. 2016;5:3425-32.

13. Angeline Grace G, Bella Devaleenal D, Natrajan M. Genital Tuberculosis in Females. Indian Journal of Medical Research. 2017;145(4):425.

Cite this article as: Yadav S, Kumar N. A prospective study of outcome in infertility patients diagnosed with genital tuberculosis. Int J Reprod Contracept Obstet Gynecol 2020;9:545-8. 